\title{
Maquiavel: do cosmos medieval ao renascentista, a fortuna e as circunstâncias da liberdade
}

\author{
Maquivel: From the medieval to the renaissance \\ cosmos, fortuna and the circumstances of freedom
}

* Flávia Roberta Benevenuto de Souza

\begin{abstract}
Resumo: As circunstâncias se apresentam como definitivas quando se pretende executar qualquer tipo ação humana, especialmente aquelas que dizem respeito à conquista e à manutenção do poder. Admitindo-se que quanto maior a força da fortuna menor a liberdade para efetivar ações capazes de conduzir o ator político ao êxito no mundo da contingência, torna-se imprescindível saber até que ponto ela exerce poder sobre as ações dos homens. Mas será possível precisálo? Partimos do contexto histórico em que as obras de Maquiavel foram escritas para compreender a relação que o autor estabelece com a tradição, ora assumindo-a, ora a ela se opondo. Recuperamos os textos de Maquiavel e estabelecemos, então, diálogo com alguns comentadores da obra do autor para investigar a questão da fortuna propriamente dita. Palavras-chave: Maquiavel. Fortuna. Circunstâncias. Liberdade.
\end{abstract}

\begin{abstract}
The circumstances present themselves as definitive when trying to run any human action, especially those that relate to the achievement and maintenance of power. Assuming that the higher the power of fortune less freedom to commit actions that can lead to successful political actor in the world of contingency, it becomes essential to know how it exercises power over the actions of men. But is it possible to do it precisely? We start from the historical context in which the works of Machiavelli are written to understand the relationship the author establishes with tradition, sometimes taking it, now opposing it. We recovered Machiavelli's texts and established dialogue with some commentators the author's work to investigate the question of fortune itself.
\end{abstract}

Keywords: Machiavelli. Fortune. Circumstances. Freedom.

* Doutora em Filosofia, Universidade Federal de Minas Gerais (UFMG). Pós-Doutorando, Departamento de Filosofia, Universidade de São Paulo (USP), com financiamento do CNPq. Professora Adjunta, Universidade Federal de Alagoas (UFAL). <flaviabenevenuto@gmail.com>. 
Se procurássemos pela origem do termo fortuna, depararíamos talvez com um momento histórico tão antigo quanto a própria origem da filosofia, talvez até mais antigo que ela. Nota-se uma grande quantidade de significados assumidos pelo termo. Thomas Flanagan, ao investigar a questão, apresenta uma lista de "usos" que podem, em contextos específicos, ser pensados como sinônimos de fortuna. De acordo com ele, "todas estas concepções se referem aos diferentes aspectos ou momentos da experiência fundamental em que o homem não tem controle total sobre o seu destino na terra". ${ }^{1}$ Deste modo, o termo fortuna apresenta muitas acepções ${ }^{2}$ e, de acordo com Flanagan, são de difícil dissociação. Ele recorre à estrutura do termo latino "fortuna" que, de acordo com ele, constitui-se como um adjetivo, a partir do substantivo fors, que significa 'sorte', associado ao verbo ferre, 'trazer'. ${ }^{3}$ Ao prosseguir em sua análise e, especificamente ao tratar as origens do termo fortuna no pensamento de Maquiavel, Flanagan parece reconstruir o percurso das interpretações apontadas por comentadores da obra de Maquiavel. ${ }^{4}$ Aponta alguns autores que teceram comentários sobre a obra de Maquiavel e suas respectivas "origens" do termo fortuna no pensamento do secretário florentino. O primeiro deles é Joseph Mazzeo. Ele "sugeriu que Maquiavel desenhou sua noção de fortuna a partir de Políbio". ${ }^{5} \mathrm{Na}$ sequência Flanagan apresenta a perspectiva de J. H. Whitfield, para quem Maquiavel 'obviamente' herdara a discussão entre virtù e fortuna dos 'Historiadores Latinos'. ${ }^{6}$ Flanagan completa sua apresentação afirmando haver uma relação entre a percepção que Maquiavel tinha da dos termos virtù e fortuna e a percepção de autores que o antecederam.O autor, no entanto, menciona haver certo exagero nas similaridades apresentadas, por exemplo, pelos autores supracitados. ${ }^{7}$ Parte deste trabalho pretende investigar esse "exagero" nas similaridades, presentes nas afirmações de autores que tendem a desconsiderar as modificações pelas quais o termo fortuna passou até ser analisado por Maquiavel.

Maquiavel parte to termo fortuna tomando-o da concepção da deusa romana, um sentido muito antigo do termo. Ele sugere se remeter à deusa

1 FLANAGAN. The History of the Goddess Fortuna. In: PAREL, Anthony. The Political Calculus: Essays on Machiavelli's Philosophy, p. 128.

2 Cf. Ibidem, p. 127.

3 Esta acepção, segundo o autor, apresenta similaridades ao termo grego equivalente, 'tyche'. Cf. FLANAGAN, Thomas. The History of the Goddess Fortuna. In: PAREL, Anthony. The Political Calculus: Essays on Machiavelli's Philosophy, p. 129-130.

4 Cf. FLANAGAN. The History of the Goddess Fortuna. In: PAREL, Anthony. The Political Calculus: Essays on Machiavelli's Philosophy, p. 133-134.

5 Ibidem, p. 133.

6 Ibidem, p. 133.

7 Ibidem, p. 134. 
pagã dos antigos romanos que assume, em certo sentido, o lugar antes ocupado em parte pelo "destino", tal como os gregos o tratavam. Essa acepção é apontada, por exemplo, por Hannah Pitkin. ${ }^{8}$ A autora parte da argumentação de Flanagan e parece corroborá-la, pelo menos no que diz respeito aos significados assumidos pelo termo fortuna. Ao fazê-lo, confere atenção especial ao seu correspondente grego, tyche. Nesta acepção afortuna, que passa a assumir a imagem da roda dos tempos da qual nada escapa, é marcada pelo determinismo, talvez tão fatídica quanto o "destino" grego. O termo, no entanto, uma vez associado à figura de uma deusa, assume determinadas peculiaridades. A deusa Fortuna dos Romanos se impõe sobre o "destino" dos homens e estes aos seus caprichos dificilmente podem resistir. De fato, a recorrência com que Maquiavel faz a utilização romana do termo fortuna é clara em suas obras políticas, com destaque para os Discorsi. Mas será que esta alusão aos antigos romanos e sua roda dos tempos, em grande medida determinista, fatalista, resume o significado do termo no pensamento de Maquiavel? A resposta a esta questão parece ser não. Esta perspectiva fatalista da força que a fortuna exerce sobre os antigos romanos pode ser observada mais de perto por meio de obras clássicas certamente lidas por Maquiavel, sendo uma delas a de Políbio. Gérard Colonna d'Istria e Roland Frapet abordam a questão da fortuna e a forma como o termo aparece nos textos de Políbio e indicam alguns dos usos que Maquiavel faz do texto a partir das Histórias de Políbio. ${ }^{9}$ Apontam, entretanto, distinções entre o uso que os dois autores fazem do texto no sentido de evidenciar "que a concepção maquiaveliana do tempo e de como as coisas acontecem no mundo impede a concepção finalista de Políbio". ${ }^{10}$ Mas, de acordo com os autores, a principal oposição de Maquiavel a Políbio seria mais específica: "Maquiavel se opõe categoricamente à principal ideia de Políbio, segundo a qual a conquista romana seria o exemplo mesmo da execução de um plano estabelecido pela fortuna e bem conduzido por ela, somente por ela". ${ }^{11}$

Embora Maquiavel se valha desta perspectiva, ela não resume o conjunto de significados que o termo assume ao longo dos seus textos. Assim, no que diz respeito aos exemplos que o inspiram, se, por um lado, os romanos se configuram como seus exemplos antigos por excelência,

PITKIN. Fortune is a Woman: Gender \& Politics in the Thought of Niccolò Machiavelli, p. 138.

9 Não trataremos da influência da obra de Políbio sobre a obra de Maquiavel neste trabalho. Apontamos o assunto apenas enquanto ele diz respeito diretamente à origem do termo fortuna e às formas de utilização dele.

10 COLONNA D'ISTRIA; FRAPET. L'Art Politique chez Machiavel, p. 181. De acordo com os autores "a Fortuna dirige as coisas humanas" (ver p. 181).

11 Ibidem, p. 181. 
por outro, não constituem sua única fonte. André Rélang, a este respeito, afirma que,

tomando por tema a noção de fortuna (com suas variações boa fortuna e infortúnio), Maquiavel não ignora que ele é herdeiro e seguidor de uma tradição rica que podemos retomar ao menos em Homero em meio aos poetas, em Aristóteles entre os filósofos passando por outros como Plutarco, Políbio, Petrarca, Bruno e Dante. ${ }^{12}$

Por outro lado, homem sempre alinhado aos acontecimentos de seu tempo, o autor não negligencia os exemplos modernos, nesta questão e nem no que diz respeito às demais. Mais que isso, Maquiavel recorre ainda à noção do termo tal como ele foi incorporado pelo senso comum. A sequência da argumentação de Rélang nos remete justamente a este ponto. Segundo ele, apesar desta relação estabelecida e assumida com a tradição, Maquiavel, ao tratar a noção de fortuna, recorre, segundo ele, à "quintessência da sabedoria popular". ${ }^{13}$ Nesse sentido, logo em seguida, afirma o seguinte: "opinião sobre a que é importante dar uma réplica porque, como a 'doxa', ela não se limita a oferecer uma representação de mundo, ela institui um tipo particular de relação com o real (...): ela já é uma atitude e uma opção sobre o que virá". ${ }^{14}$ Desse modo, a atitude de Maquiavel diante daquilo que não pode ser controlado pelos homens parece só poder ser inteligível se pensada a partir de seu contexto específico.

Podemos dizer assim que a questão da fortuna, tal como ela aparece no pensamento de Maquiavel nos remete imediatamente ao contexto histórico da época: o fatalismo da concepção pagã, a tentativa de ultrapassar este fatalismo pela compreensão da conciliação entre Providência Divina/livre-arbítrio cristão medieval e o espírito da liberdade republicana renascentista que insurgia. Filho de seu tempo, Maquiavel, se inscreve em todos eles sem, no entanto, se prender a nenhum. Estas distintas perspectivas se configuram todas elas como pertinentes (haja vista suas distinções por vezes radicais) para a compreensão do contexto em que Maquiavel escreveu e consequentemente dos posicionamentos que ele assume em seus textos. Tal como afirmam os autores Gérard Colonna d'Istria e Roland Frapet, a obra de Maquiavel apresenta uma "novidade radial" 15 e "é verdade que ela possui todas as características e todas as ambiguidades de um pensador que tenta romper com uma longa tradição e anuncia tempos novos". ${ }^{16}$ Maquiavel, de fato, rompe

\footnotetext{
12 RÉLANG. La Dialectique de la fortuna et de la virtù chez Machiavel, p. 650.

13 Ibidem, p. 650.

14 Ibidem, p. 650.

15 Cf. COLONNA D'ISTRIA; FRAPET. L'Art Politique chez Machiavel, p. 207.

16 COLONNA D'ISTRIA; FRAPET. L'Art Politique chez Machiavel, p. 207.
} 
com a tradição. Melhor dizendo, assume a tradição, transgredindo-a em inúmeros aspectos. Naquilo que diz respeito à fortuna, assume seu legado conceitual, rompendo indiretamente com uma tradição que se edificava desde os gregos a partir do rompimento direto com as afirmações de Cícero e Políbio. Este rompimento não se dá apenas em relação àquilo que diz respeito à política, mas parece se estender a outros âmbitos.

Por causa disso, ao recuperarmos alguns dos elementos pertencentes a este contexto, precisamos compreender que não se trata de recuperar somente aquilo que diz respeito diretamente ao âmbito político, mas, e além dele, o contexto dellascientia, assim como sua influência nas concepções que se formavam no âmbito público. A primeira coisa a que precisamos nos ater quando tratamos da fortuna, no contexto em que se inscreve o pensamento de Maquiavel, é que é preciso deixar de lado a separação moderna existente entre âmbitos distintos da scientia. Naquilo que diz respeito à fortuna, por exemplo, o contexto político não pode ser dissociado do astro-físico. Parece ser antes influenciado por ele. Mais que isso, estes dois âmbitos se complementam. Em um tempo marcado pela sede de novidades e em que todos os olhares se voltam em grande medida para os astros, não havia âmbito do saber que ignorasse as novas descobertas. Neste sentido, as concepções que se constituíam a partir da investigação do cosmos influenciavam as ações dos homens no âmbito público. Naquilo que diz respeito à fortuna, há uma tentativa de identificá-la em função de uma determinada compreensão do cosmos. Mais que isso, a maneira como os homens concebiam a força ou a interferência da fortuna em suas vidas ou mesmo no corpo político poderia alterar seu modo de agir, e talvez este seja um dos principais pontos que conferem a tal questão um lugar tão especial no pensamento de Maquiavel. Antes, porém, de tratarmos da influência direta da fortuna nas ações dos homens, precisamos tentar compreendê-la e, em especial, precisamos fazê-lo tendo em vista os mesmos mecanismos em que isso era feito no contexto vivido pelo autor.

\section{Fortuna e cosmologia: uma nova concepção de liberdade}

Gérard Colonna d'Istria e Roland Frapet apontam que, pelo menos como ponto de partida, o termo fortuna pode ser tomado como aquilo que há de irracional no domínio da política. ${ }^{17}$ Se esta afirmação é verdadeira, parece sê-lo também a tentativa de investigar isto que há de indeterminado no campo da política por via do estudo do cosmos. Se nos voltamos mais especificamente para Maquiavel, percebemos

17 COLONNA D'ISTRIA; FRAPET. L'Art Politique chez Machiavel, p. 179. 
que a Renascença se constituía, de fato, como um momento em que o estudo dos astros, do cosmos, do universo não somente estava em voga, como também passava por um momento de transição. A antiga estrutura cósmica medieval, marcada pelo determinismo de uma força divina, vinha de pouco em pouco cedendo espaço a perspectivas cada vez menos relacionadas à ordem religiosa vigente e, consequentemente, cada vez menos deterministas. Pensar a fortuna remete-nos assim ao contexto histórico de Maquiavel, tomando-o a partir de sua concepção de cosmos. Concepção esta circunscrita neste período de transição de conceitos, fato que impõe certa atenção à sua investigação. Podemos dizer até que o estudo dos astros, do cosmo no período do Renascimento, se desenrola em um ambiente complexo, ligado à magia e marcado por preceitos religiosos. Isto, segundo Eugenio Garin, se deve, em especial, a uma questão histórica. Segundo ele,

no Renascimento e no que diz respeito à astrologia aparece uma distinção entre os dois aspectos desta disciplina: religioso e supersticioso de um lado, crítico e científico de outro; enquanto na Antiguidade e na Idade Média eram relacionados e misturados até serem confundidos sob o termo único de astrologia. ${ }^{18}$

O tempo de Maquiavel coincide com o momento em que estas questões são analisadas com mais clareza, com alguma divisão teórica. Entretanto, não se pode desconsiderar que a época de Maquiavel ainda é marcada pela influência do modelo medieval - em grande medida engajado em conciliar Liberdade e Providência Divina no universo determinado por Deus - e, ao mesmo tempo, pela modificação deste sistema assim como pela recuperação de alguns elementos próprios da Antiguidade clássica abandonados no período medieval. Podemos dizer, generalizando, que, ao mesmo tempo que questões tradicionalmente discutidas no período medieval (como a conciliação entre livre-arbítrio e providência divina) são mantidas, a forma de se conceber a liberdade se altera um pouco. $O$ indivíduo, embora preso a forças que lhe são superiores e que, direta ou indiretamente, nele interferem, parece mais autônomo, mais responsável pelas suas ações e pelo resultado produzido por elas.

Assim, de acordo Gérard Colonna d'Istria e Roland Frapet,

a afirmação de um continente político autônomo implica o abandono da ideia de uma finalidade da natureza ou da providência divina. Um cosmos conduzido a um tempo e a uma ordem da Natureza privada de finalidade - na qual se insere a ideia de fortuna - conduzida à emergência de um

18 GARIN. Le Zodiaque de la Vie: polémiques antiastrologiques à la renaissance, p. 19. 
universo político autônomo e de uma arte política que não se situa mais no interior de uma hierarquia cosmológica e não é mais tratada tendo em vista uma finalidade moral transpolítica. ${ }^{19}$

Essa nova possibilidade, no entanto, se abria em função de uma mudança profunda na forma de compreender o universo, o cosmos e a fortuna, assim como a capacidade que estes poderiam ter de interferir na vida dos homens. Esse novo modo de lidar com o cosmos, de perceber a fortuna nos interessa em função das alterações que foi capaz de provocar no âmbito público e enquanto condição de possibilidade para a realização dos objetivos de Maquiavel. Ernest Cassirer, ${ }^{20}$ ao abordar a questão do cosmos, também trata do Renascimento como um período de grandes transformações que se devem, em grande medida, a uma nova forma de se conceber o mundo. Forma esta que altera a maneira como o homem se vê no mundo e, em especial, a relação mais livre que é capaz, a partir de então, de estabelecer com este. ${ }^{21}$

Tudo isso parece constituir o ambiente no qual Maquiavel pensa a política. Mesmo assim o autor parece não somente ter seguido uma tendência de pensamento de sua época, mas ter ainda contribuído para sua concretização definitiva na história. Sfez afirma ao iniciar seu livro, Machiavel, la politique du moindre mal, que "a obra de Maquiavel - de O Príncipe aos Discorsi - foi saudada como uma demonstração da potência da liberdade humana face à pretendida fatalidade da Fortuna". ${ }^{22} \mathrm{Na}$ sequência do texto ele afirma não invalidar a conclusão, mas a problematiza apontando uma resistência que segundo ele se faz dupla. "Não seria [a fortuna] o nome daquilo que resiste à nossa liberdade?", questiona Sfez. ${ }^{23}$ Ao inverter a questão, ele nos chama a atenção para o fato de ser o seu poder um poder de resistência que se revela duplo: "resistência da Virtù, resistência da Fortuna". ${ }^{24}$ De acordo com ele, esta atitude de Maquiavel pode ser tomada "como um ato de ruptura com a herança renascentista". ${ }^{25}$ Isto porque, ainda segundo Sfez, "era grande a tentação, diante das dificuldades de se chegar aos seus fins, se remeter à providência divina ou à fortuna e se renunciar a esperar alguma coisa da ação". ${ }^{26}$

19 COLONNA D'ISTRIA; FRAPET. L'Art Politique chez Machiavel, p. 207.

20 Ver CASSIRER. Individu et Cosmos: dans la Philosophie de la Renaissance.

${ }^{21}$ Neste sentido, um caso interessante e muito conhecido um pouco posterior a Maquiavel, mas que nos auxilia a compreender melhor estas modificações no modo de o homem compreender sua inserção no universo, é o de Galileu.

22 SFEZ. Machiavel, la politique du moindre mal, p. 23.

23 Ibidem.

24 Ibidem.

25 Ibidem, p. 24.

26 Ibidem. 
Nesse sentido, se havia já uma abertura maior para se pensar o cosmos e sua influência na vida dos homens como menos implacável, ainda era difícil pensar em grande liberdade em relação a ele. Maquiavel, tal como parece ter feito em relação também a outras questões, dá sequência àquilo que se pensava em sua época ao mesmo tempo que introduz certo rompimento. Neste caso especificamente introduz uma forma alternativa de pensar a ação humana que não se reduz a ser controlada exclusivamente nem pela providência divina cristã nem pela cosmologia aristotélica. ${ }^{27}$

Anthony Parel nos ajuda a compreender melhor os termos da relação que Maquiavel estabeleceu com a forma como o cosmos era percebido em seu tempo. Ele nos oferece um panorama mais específico da questão. ${ }^{28} \mathrm{Em}$ seu The Machiavelian Cosmos, ele investiga a fortuna sob a perspectiva da cosmologia, ou seja, de modo geral, sob a perspectiva da ciência natural renascentista. ${ }^{29}$ Parte do pensamento de Ptolomeu, ${ }^{30}$ que, segundo ele, pode ser observado em alguns aspectos d'O Príncipe. ${ }^{31} \mathrm{Mas}$, antes de tratar diretamente da questão da fortuna no pensamento de Maquiavel, investiga o impacto das obras de Ptolomeu e Abu Ma'shar no pensamento cosmológico renascentista. O ponto de partida parece ser o fato de que "nem tudo que acontece no mundo tem uma explicação causal na atividade intencional de agentes inteligentes". ${ }^{32}$ Volta-se então à análise da obra de Maquiavel e à questão da fortuna.

Ao tratá-la, afirma que a questão passa necessariamente pela concepção de cosmologia que Maquiavel herdara de sua época e, ao mesmo tempo, por algumas novidades introduzidas pelo pensamento do autor. ${ }^{33}$ Segundo ele, "o império do céu e da fortuna cedem um limite

${ }_{27}$ Ver a este respeito, COLONNA D'ISTRIA; FRAPET. L'Art Politique chez Machiavel, p. 193.

28 Segundo Parel, muitos dos comentadores da obra de Maquiavel constataram a existência do tema da astrologia nos textos deste autor (ele cita diretamente Ernst Cassirer, Hans Baron, Leo-Strauss, Eugenio Garin, que segundo Parel foi mais longe que os outros, e Gennaro Sasso). Mas, segundo ele, seu The Machiavelian Cosmos não tem por objetivo simplesmente constatar esta existência (que considera incontestável). Objetiva investigar, em suas palavras, "sua extensão e seu significado" (PAREL. The Machiavelian Cosmos, p. 6).

29 Vale lembra que Parel inicia The Machiavellian Cosmos criticando Burkhardt pela sua pouca atenção ao tema, assim como por "não ver nada positivo na astrologia" (PAREL. The Machiavelian Cosmos, p. 2).

30 Ver capítulo 1: The Astrological Debate. In: PAREL. The Machiavelian Cosmos, p. 11-25.

31 De acordo com Parel, "algumas das ideias de Ptolomeu são particularmente relevantes para a proposta que temos em mãos. Na primeira parte da tese ele divide a astrologia em duas partes maiores: a geral, ou católica, e a particular, ou genética. A primeira compreende as fortunas e ethos dos Estados, enquanto a segunda compreende os temperamentos e fortunas dos indivíduos. A influência desta divisão entre astrologia geral e particular pode, penso eu, ser detectada no tratamento mais famoso que Maquiavel dá à fortuna no capítulo XXV do Príncipe" (PAREL. The Machiavellian Cosmos, p. 12).

32 PAREL. The Machiavelian Cosmos, p. 23.

33 Cf. PAREL. The Machiavelian Cosmos, p. 63. 
para que a autonomia humana possa se efetivar". ${ }^{34}$ Neste ponto, podemos identificar um espaço maior para que o homem pudesse se pensar mais livre em relação ao universo do que em momentos anteriores da história. Seguindo a argumentação de Parel, encontramos outros trechos que parecem guiar-nos na mesma direção:

No cosmos maquiaveliano não há lugar para Providência Divina, embora haja espaço tanto para céu quanto para fortuna; ele cede espaço para esses porque apontam para dois tipos causais distintos, um pertencente à necessidade e outro ao que é fortuito. ${ }^{35}$

Esta afirmação de Parel nos conduz a refletir sobre o pensamento de Maquiavel e seu lugar na tradição. Tal como afirma em seu artigo publicado em francês com o título Ptolomé et le Chapitre 25 du Prince, "a forma como as coisas humanas e as coisas do mundo eram governadas era a questão mais debatida na Florença de Maquiavel. A discussão, conhecida historicamente como disputa da astrologia, revela a atualidade do capítulo 25". ${ }^{36}$ Assim, Maquiavel se põe a pensar sua época e, ao mesmo tempo que rompe com a tradição cristã, não rompe em definitivo com sua época e com os valores da tradição. Parel parece não ignorar esta possível ambivalência existente entre o pensamento de Maquiavel e a tradição. Ele recupera o poema Di Fortuna e, na sequência, o capítulo XXV d'O Príncipe no intuito de investigar a questão.

No primeiro, segundo ele, a fortuna está associada ao céu. ${ }^{37}$ No segundo, afirma que "o homem aparece em primeiro plano e a natureza em segundo e a fortuna sempre pode controlar ambos". ${ }^{38}$ Neste sentido, e em especial a partir desta constatação, Parel argumenta a favor não de um rompimento que teria sido efetuado por Maquiavel em relação ao sistema astrológico próprio de sua época, mas de uma adaptação deste modelo. Segundo ele, "pode parecer que Maquiavel abandona a solução astrológica clássica, (...) [mas] longe de abandonar o modo de compreensão astrológico, ele o adapta à sua maneira". ${ }^{39}$ Destarte, a partir do momento em que Maquiavel relaciona suas hipóteses a uma concepção cosmológica por ele "adaptada", abre espaço para se pensar o lugar do homem, assim como suas relações, de forma distinta da tradição. A principal diferença parece ser justamente naquilo que diz respeito às questões que se relacionam à liberdade.

\footnotetext{
34 PAREL. The Machiavelian Cosmos, p. 63.

35 Ibidem, p. 65-66.

36 PAREL.Ptolomé et le Chapitre 25 du Prince. In: SFEZ; SENELLART. L'Enjeu Machiavel, p. 25.

37 Cf. PAREL. The Machiavelian Cosmos, p. 74.

38 Ibidem, p. 76.

39 Ibidem.
} 
Embora a argumentação de Parel nos pareça razoável até este ponto, encontramos aqui certa hesitação em seu texto. Ele chama de adaptação do modelo tradicional o que acreditamos ser um rompimento com este modelo. Um rompimento definitivo que partia da aceitação de elementos da tradição como uma estratégia de argumentação. Maquiavel, assim como era comum aos autores humanistas de seu tempo, habituado à arte retórica, sabe que refutar de imediato uma opinião amplamente aceita por um determinado público (entimema) ${ }^{40}$ não contribuirá para a modificação desta opinião já admitida. Aceitando-se que o discurso tem por fim substituir uma opinião prévia por outra, é preciso admitir pontos comuns entre as duas premissas para captar atenção do expectador e tentar então conduzi-lo a outra perspectiva, ou seja, tentar persuadi-lo. Maquiavel não pode refutar de forma prévia e sumária o discurso religioso, no caso cristão, nem com o discurso astrofísico tradicional. Ele sabe que só poderia se fazer ouvir admitindo pontos destes discursos e, somente a partir desta admissão inicial, poderia introduzir um novo modo de pensar a ação humana e as possíveis influências da fortuna que recaem sobre ela. Este procedimento não parece implicar uma adaptação da tradição, pois era o método usado por uma longa tradição intelectual, por aqueles que desejam introduzir mudanças difíceis de serem admitidas por seus expectadores em função de terem daquele assunto uma opinião contrária. Preferimos acreditar que Maquiavel inova em sua proposta teórica por meio de um recurso discursivo tradicional. Assim, ao pretender modificar a concepção da liberdade da ação humana no espaço público, vale-se de meios capazes de efetivá-lo (mesmo que sob pena de diminuir aos olhos do leitor a novidade das proposições que enuncia). ${ }^{41}$

40 Referimos-nos aqui a uma designação própria do vocabulário do estudo da arte retórica. De acordo com o que afirma Roland Barthes "o entimema recebeu duas significações sucessivas (que não são contraditórias). 1. Para os aristotélicos, é um silogismo fundamentado em verossimilhanças ou em sinais, e não sobre algo de verdadeiro ou de imediato (como é o caso do silogismo científico); o entimema é um silogismo retórico, desenvolvido unicamente no nível do público (como se diz: colocar-se no lugar de alguém), a partir do provável, isto é, a partir daquilo que o público pensa; é uma dedução cujo valor é concreto, colocado em vista de uma apresentação (é uma espécie de espetáculo aceitável), por oposição à dedução abstrata, feita unicamente pela análise: é um arrazoado público, manipulado facilmente por homens incultos. Em virtude desta origem, o entimema obtém a persuasão, não a demonstração (...). 2. Desde Quintiliano e com total triunfo na Idade Média (desde Boécio), uma nova definição prevalece: o entimema é definido não pelo conteúdo de suas premissas, mas pelo caráter elíptico de sua articulação: é um silogismo incompleto, um silogismo encurtado: 'não tem tantas partes nem partes tão distintas quanto o silogismo filosófico': pode-se suprimir uma das premissas ou a conclusão: é então um silogismo truncado pela supressão (no enunciado) de uma proposição cuja realidade aparece aos homens incontestável e que é, por esta razão, simplesmente 'retida na mente' (enthumô)". (BARTHES. A aventura semiológica, p. 57-58).

41 Sabemos que este é um assunto controvertido entre os comentadores do pensamento de Maquiavel. Discuti-lo nos desviaria do nosso problema central. Em função disto, optamos por mencioná-lo apenas, sem deixar de assumir um posicionamento em relação ao tema. Acreditamos que o autor objetivava efetivamente mitigar a inovação que introduzia para facilitar a plausibilidade e, portanto, a aceitação de sua proposta. 
Deixando de lado este assunto e voltando à argumentação de Parel, partindo agora do capítulo XXV d'O Príncipe, sua análise chama nossa atenção para duas questões que também dizem respeito a esta guinada maquiaveliana: a relação da fortuna com o temperamento dos homens e sua relação com a qualidade dos tempos. No primeiro, caso Parel afirma que, apesar de a fortuna relacionar-se melhor ou pior com os diferentes humores ou temperamentos dos homens, "empiricamente, podemos ver que pessoas com o mesmo temperamento não alcançam os mesmos resultados. (...) Este fenômeno reflete a regra da 'variação dos tempos' em que o sucesso é obtido em um ponto específico do tempo e em outro ponto pode falhar". ${ }^{42}$ Neste sentido, Aranovich, ao analisar o poema $\mathrm{Di}$ Fortuna, afirma que "a fortuna é constantemente inconstante: é de sua natureza ser volúvel e móvel" 43 . Mais adiante, a autora completa seu argumento afirmando que

a Fortuna é poderosa e inconstante, mas não inteiramente imprevisível, pois sua imprevisibilidade se refere apenas ao tempo, isto é, não se pode prever quando ela mudará os giros. Há, no entanto, constância na inconstância, pois não se pode prever quando, mas é certo que o momento da mudança virá, posto que é uma roda. (...) Há altos e baixos, elevação e derrota, nunca o meio-termo. ${ }^{44}$

A introdução de variações postas pela fortuna pode, então, se dar imediatamente ou daqui a um século, dois, cinco, não se pode saber. Por isto, estas questões se relacionam, em certa medida, com a perspectiva que Maquiavel tem da história. Esta última, que lhe serve de ferramenta para analisar as possibilidades de ação do governante em um determinado momento, pode se tornar o único refúgio diante das variações impostas pela fortuna. A recorrência à história pode se fazer eficaz apesar da inconsistência de um modelo acabado diante desta fonte de variação desmedida e incontrolável. É válida como uma possibilidade de se analisarem tais variações e pensar meios de resistir a elas.

Entretanto, há muitas dificuldades no tratamento da questão da fortuna quando se tenta generalizá-la. Talvez por isso Maquiavel tenha dividido sua análise em dois âmbitos. Parel segue a divisão introduzida por ele e investiga, em um primeiro momento, a fortuna naquilo em que ela afeta um determinado corpo político e, mais tarde, naquilo em que ela afeta os indivíduos. De acordo com ele, esta divisão não pode ser afirmada sob uma mesma medida. Conclui, neste sentido, que "Maquiavel

42 PAREL. The Machiavelian Cosmos, p. 77.

43 ARANOVICH, P. F. Di Fortuna e a Fortuna em Maquiavel. "Cadernos de Filosofia Política", p. 222.

44 Ibidem, p. 223. 
se dedica mais a analisar a fortuna naquilo em que ela afeta os indivíduos que naquilo em que ela afeta os países". ${ }^{45} \mathrm{E}$, ainda segundo Parel, quando o assunto é a fortuna dos indivíduos, duas coisas estão em questão: o tempo e a natureza. A natureza (natura: humor/temperamento) de um determinado indivíduo pode concordar ou não com a natureza dos tempos, e do resultado desta concordância ou discordância se dá o seu sucesso ou sua ruína. ${ }^{46}$

Não podemos ignorar que esta divisão não passou despercebida aos comentadores da obra de Maquiavel. Faraklas, ao tratar "as paixões políticas", 47 também a evidencia. Parece indicar que, por um lado, enquanto é necessário resistir à fortunain universali, pode-se dizer, por outro lado, que no caso da fortunain particulari, da boa fortuna, faz-se necessário ao ator político adequar-se ao acaso. De modo mais específico, o autor afirma que a fortunain universali nos remete "ao acaso, à necessidade exterior que uma vez determinante na tomada de decisão não se desprende dela". ${ }^{48}$ Já no caso da fortunain particulari, parte-se do pressuposto de que "somente a adaptação oportuna conserva o mesmo capitão junto à tropa". ${ }^{49}$ Colonna d'Istria e Frapet também investigam a questão. Ao analisarem os textos de Políbio e uma possível relação entre estes e a obra de Maquiavel,,$^{50}$ embora por um caminho mais longo (haja vista que Maquiavel não incorpora o sentido finalista do qual se valia Políbio), encontram uma distinção parecida, apesar de não definida por estes mesmos termos. ${ }^{51}$

Mesmo havendo algumas distinções entre as designações apresentadas pelos comentadores da obra de Maquiavel, estes dois âmbitos distintos, assim como suas peculiaridades, parecem lhes ser coincidentes. Para explorá-las um pouco mais de perto, recorreremos aos textos de Maquiavel, mais especificamente ao Príncipe e ao Discorsi, no intuito de não deixar de lado elementos importantes para a compreensão tanto do que Maquiavel aponta como fortuna, quanto das peculiaridades que o tratamento desta questão adquire ao longo de suas obras.

45 PAREL. The Machiavelian Cosmos, p. 74.

46 Ibidem, p. 77.

47 Ver FARAKLAS. Machiavel: Le Pouvoir du Prince, p. 50-88.

48 Ibidem, p. 52.

49 Ibidem.

50 Vale lembrar que a comparação e a possível influência dos textos de Políbio sobre os de Maquiavel apresentada pelos autores parece não ter o objetivo de evidenciar apenas as coincidências entre o pensamento dos dois, mas também os pontos em que suas obras não são coincidentes. Ao invés disso, os autores chegam a afirmar que "através da comparação com Políbio foi esclarecida a originalidade do conceito de Fortuna em Maquiavel" (COLONNA D'ISTRIA; FRAPET. L'Art Politique chez Machiavel, p. 193).

51 Ver COLONNA D'ISTRIA; FRAPET. L'Art Politique chez Machiavel, p. 179-193. 
F. R. B. de Souza - Maquiavel: do cosmos medieval ao renascentista...

\section{O que pode a fortuna afinal?}

Vimos que Maquiavel compreende o homem mais livre do que as concepções vinculadas à religião cristã ou à tradição cosmológica. Esta liberdade, no entanto, parece ser ainda limitada pelas circunstâncias que a todo o momento exigem que o governante efetive suas ações de uma maneira específica, sob pena de perder o poder do corpo político. Se aquela que impõe tais modificações circunstanciais é a fortuna, então precisamos verificar se é possível compreender melhor os limites do seu poder. Esta investigação nos conduzirá consequentemente a analisar melhor as variações das circunstâncias e, em última instância, a vislumbrar mais de perto as possibilidades efetivas de liberdade da ação humana no espaço público. Para tentarmos compreender melhor as possibilidades da fortuna, partiremos da obra que nos parece ser a mais apropriada para a análise da questão: O Príncipe. A questão da fortuna aparece em todas as obras políticas de Maquiavel, permanecendo um tema recorrente também em seu legado. O Príncipe, porém, é uma obra que tende a lidar com a ação política no seu caráter mais emergencial, é também nele que a fortuna é apresentada de forma mais apelativa e, talvez por ser apresentada em seus extremos, poderíamos dizer também de forma mais explícita. ${ }^{52}$

Analisar O Príncipe, especialmente seu capítulo XXV, que diz respeito diretamente à questão da fortuna, faz-se fundamental neste trabalho, mas não podemos nos esquecer de que o príncipe novo não encarna a figura do ator político mais importante no pensamento de Maquiavel. Sua urgência pode tornar uma análise sobre este gênero mais clara, mas acreditamos que os atores republicanos assumem peso equivalente no pensamento do autor. Sob alguns aspectos talvez até um peso maior, tal como afirma Pancera: "entre o principado e a república, esta última é a forma de governo que melhor se conforma às novas exigências". ${ }^{53}$ Neste sentido, tomar o príncipe novo em detrimento dos atores republicanos nos conduziria a uma falta de precisão naquilo que diz respeito à questão da fortuna. Tentaremos evitar este desvio apesar da força das passagens d'O Príncipe e recorreremos, embora de forma menos direta, também aos Discorsi, que nos oferecem a possibilidade de refletir sobre a análise que Maquiavel faz dos antigos romanos e, consequentemente, sobre os

52 Assumimos aqui parte da tese de Pocock que vislumbra a urgência enunciada na obra O Príncipe e que, segundo o comentador, se fundamenta pelo objetivo de pensar as possibilidades do príncipe novo. Este último, ainda segundo o autor, carece de legitimidade e, em função disso, ficaria mais vulnerável à fortuna (Ver POCOCK. The Machiavellian Moment, p. 158-159). Este seria um dos motivos que tornam o assunto tão relevante e peculiar na obra $O$ Príncipe.

53 PANCERA. Maquiavel entre Repúblicas, p. 13. 
desígnios da fortuna sobre a República. Esperamos, dessa forma, poder vislumbrar um panorama mais completo da utilização do termo, assim como das dimensões que ele assume na obra do autor.

Maquiavel, tal como vimos, se apropria inicialmente do uso que os romanos faziam do termo fortuna, a deusa da roda dos tempos, que se apresenta, tal como afirma Bignotto, "como aquela que retira dos homens tudo aquilo que conquistaram quando decide mudar o rumo das coisas sem aviso prévio". ${ }^{44}$ Este ponto de partida da utilização que Maquiavel faz do termo nos remete diretamente a uma reflexão sobre a possibilidade de liberdade da ação humana anunciada pela modificação da perspectiva cosmológica na época e suas implicações práticas. Mas as modificações que dizem respeito à estrutura cosmológica de então não implicam a única peculiaridade daquele período. ${ }^{55} \mathrm{De}$ modo geral, o homem ocupava um lugar de pouca significância no universo. Bignotto toma Santo Agostinho para afirmar que "a presença do homem no mundo era coisa sem importância, quando comparada com o lugar da plena existência humana na 'Cidade de Deus'". ${ }^{66}$ Entretanto, segundo o autor, "a concepção republicana, própria aos humanistas, punha o homem no centro do universo, exigindo dele aquilo que, aos olhos de um pensador medieval, só a graça poderia dar". ${ }^{57}$ Esta percepção, que se distanciava dos motes clássicos do período medieval, foi, em certo sentido, fundamentada por autores clássicos da Era Pagã.

Cícero, especialmente naquilo que dizia respeito ao estudo da retórica, e a filosofia antiga foram retomados e contribuíram de forma definitiva para esta mudança de perspectiva. Trata-se de um contexto bastante complexo em que os studia humanitatis favoreceram o que passou a chamar de virtude cívica que, por sua vez, não coincidia com a virtude cristã e, ao mesmo tempo, não necessariamente a contrariava. ${ }^{58}$ No quatrocentto, de acordo com o que afirma Bignotto,

54 BIGNOTTO. Maquiavel, p. 26.

55 Precisamos considerar que o período do Renascimento é marcado por mudanças significativas que se inter-relacionam, de modo que apontar uma única mudança na estrutura de pensamento da época implica a omissão de outras. Cientes deste risco e ao mesmo tempo cientes da necessidade de não nos desviarmos de nossa questão central, podemos dizer que, de modo geral, a modificação da estrutura cosmológica (embora não somente ela) afetou diretamente a percepção do lugar do homem no mundo. Nesse sentido, perceber a questão da fortuna em função de uma maior liberdade dos homens não é exatamente uma novidade no pensamento de Maquiavel. Veremos mais adiante as peculiaridades do tratamento da questão no pensamento do autor e sabemos da importância do seu legado. Queremos apontar apenas que uma modificação de tamanha envergadura só foi possível em função de uma conjunção de fatores, não se tratando assim de uma questão pontual.

56 BIGNOTTO. Maquiavel Republicano, p. 32.

57 Ibidem.

58 Ibidem, p. 32-38. 
voltando a Cícero, recuperando suas ideias em torno da educação, eles buscavam uma nova maneira de conceber a presença do homem na terra, sem se preocuparem em fazer a crítica da tradição, dada como realizada pelo simples fato de que o universo conceitual medieval fora abandonado. ${ }^{59}$

Maquiavel bebera diretamente nesta fonte, embora saibamos que rompera com esta tradição em alguns aspectos, especialmente naquilo que diz respeito à fortuna e sua relação não necessariamente simples com a virtù, tal como veremos mais adiante. Antes, no entanto, de chegarmos a esta questão, precisamos compreender melhor a fortuna no pensamento de Maquiavel. Após ter vivenciado direta ou indiretamente tantas perspectivas distintas da fortuna, como Maquiavel a compreendia afinal? Raros seriam os motivos para partirmos da concepção cristã tradicional que herdara dos romanos alguns de seus principais fundamentos. Partindo dos humanistas, sabemos que podemos nos aproximar mais da perspectiva do autor. Mas, tendo em vista uma maior possibilidade de liberdade naquilo que diz respeito à efetividade das ações humanas, como compreender a força muitas vezes devastadora da fortuna?

Sabemos que conhecê-la efetivamente não é possível. Bignotto, a este respeito, afirma que "Maquiavel não sugere nem de longe que possamos conhecer seus desígnios". ${ }^{60}$ De fato, não podemos conhecer as causas de sua força nem mesmo suas dimensões. Podemos conhecer apenas seus efeitos. Ainda de acordo com o que afirma Bignotto, "da fortuna conhecemos apenas os efeitos e o fato de que pode sempre se manifestar, mas nunca suas vontades e o momento em que vai lançar seus fios". ${ }^{61}$ Mas, se podemos conhecer seus efeitos, parece-nos plausível analisar então os registros dos desígnios da fortuna na história, tal como o investigou Maquiavel. A respeito deles o autor sugere que ela se manifesta principalmente por meio da modificação das circunstâncias. Esta modificação por si só já parece ser nociva tanto àquilo que diz respeito ao corpo político propriamente dito quanto aos seus atores tomados individualmente. Mas por quê? Não seriam os homens capazes de improvisar e reagir às tais modificações?

Bignotto novamente nos indica a resposta. Segundo ele, "os homens amam repetir seus comportamentos e se agarram à sua forma de agir, quando ela os conduz ao sucesso". ${ }^{62}$ Agindo sempre da mesma forma, enfrentam grandes dificuldades quando o padrão adotado, em vez do êxito, passa a conduzi-los à ruína. Dessa forma, ao adotarem um

\footnotetext{
59 BIGNOTTO. Maquiavel Republicano, p. 33.

60 BIGNOTTO. Maquiavel, p. 27.

61 Ibidem, p. 27.

62 Ibidem, p. 26.
} 
determinado modo de ação e consagrá-lo sugestivo ao êxito, esquecemse de que mantêm o sucesso apenas enquanto a fortuna coincide com a maneira de agir que adotaram. Quando ela modifica as circunstâncias, não modificando os homens seus modos de ação (o que parece não ser fácil tendo em vista que tendem às repetições), tornam-se infortunados. Tal como afirma Maquiavel, "variando a fortuna e obstinando-se os homens em sua maneira de ser, eles serão felizes enquanto ambas as coisas estiverem de acordo; mas, quando elas discordarem, serão infelizes". ${ }^{63} \mathrm{~A}$ fortuna é capaz de produzir este desacordo entre os tempos e as ações dos homens e, quanto maior a distância que ela insere entre uma coisa e outra, mais sujeitos à ruína se veem os homens. Tal como sugere Aranovich, "a ação humana tem uma direção constante e busca a estabilidade, a Fortuna é volúvel e inconstante. (...) Essa incompatibilidade provoca a ruína dos que se deixam levar por ela e daqueles que não lhe opõem obstáculos"64.

Embora tenhamos, neste primeiro momento, tentado mostrar os efeitos nocivos da fortuna sobre os homens (que certamente implicam as maiores preocupações concernentes ao tema), temos que considerar ainda dois pontos: 1) nem sempre eles recaem sobre os indivíduos, podendo incidir diretamente sobre o corpo político; 2) nem sempre os efeitos da fortuna são nocivo ${ }^{65}$. No primeiro caso, a afirmação nos remete à divisão que, tal como vimos anteriormente, nos foi apresentada pelos comentadores da obra de Maquiavel. De acordo com ela, a fortuna incide, por um lado, sobre o corpo político propriamente dito e, por outro, sobre os indivíduos tomados como agentes no interior do corpo político. O vigésimo quinto capítulo d'O Príncipe, intitulado "De quanto pode a fortuna nas coisas humanas e de que modo se pode resistir-lhes", nos indica esta divisão. De fato, a forma como o capítulo foi escrito e a divisão que nele nos é apresentada confirmam a possibilidade de distinção da atuação da fortuna em sua forma mais geral e em sua forma particular. Logo após apresentar a metáfora do rio, Maquiavel afirma o seguinte: "julgo ter dito o suficiente sobre como opor-se à fortuna de modo geral.

63 MACHIAVELLI. Il Principe, XXV, p. 189: Concluo adunque che, variando la fortuna e' tempi e stando li uomini ne' loro modi ostinati, sono felici mentre concordano insieme e, come e' discordano, infelici.

64 ARANOVICH, P. F. Di Fortuna e a Fortuna em Maquiavel. "Cadernos de Filosofia Política", p. 221-222.

65 Aranovich, ao analisa o poema Di Fortuna, mais especificamente ao se debruçar sobre as afirmações de Maquiavel sobre os que se encontram no Reino da Fortuna, acaba por constatar uma das causas da má fama da fortuna: "Os homens reconhecem como provenientes da Fortuna apenas os males, reconhecendo, portanto apenas a 'má fortuna'. Os bens que obtém julgam ser fruto de sua própria virtude, o que ocasiona outra razão de má fama da Fortuna". ARANOVICH, P. F. Di Fortuna e a Fortuna em Maquiavel. "Cadernos de Filosofia Política", p. 224. 
Mas, restringindo-me aos aspectos mais particulares, digo que se vê que um príncipe tem sucesso e amanhã fracassa sem ter mudado sua natureza ou qualidade". ${ }^{66}$ Sugere ser também em função desta distinção que ele apresenta duas metáforas para tratar da questão.

A primeira delas nos remete aos fenômenos da natureza e ilustra o que os comentadores da obra identificaram como sentido geral ou universal da fortuna. Assim, a fortuna pode ser ilustrada pelas enchentes (que especialmente no Arno tantos danos provocaram a Florença) e nada pode ser feito quando ela mostra sua força. Mas muito pode ser feito para tentar neutralizar ou minimizar sua força, tal como a construção de diques minimiza a destruição de que uma enchente potencialmente é capaz. Nas palavras do autor, "comparo a sorte a um desses rios impetuosos que, quando se irritam, alagam as planícies, arrasam as árvores e as casas, arrasam as terras de um lado para levar a outro: todos fogem deles, mas cedem ao seu ímpeto, sem poder detê-los em parte alguma". ${ }^{67}$ Logo na sequência o autor parece procurar evidenciar a possibilidade de uma resistência ordenada à força da fortuna. De acordo com ele, "mesmo assim, nada impede que, voltando à calma, os homens tomem providência, construam barreiras e diques, de modo que, quando a cheia se repetir, ou o rio flua por um canal, ou sua força se torna menos livre e danosa." ${ }^{68}$ Para finalizar a apresentação da metáfora, Maquiavel se refere diretamente à fortuna e ao seu par conceitual virtù (que investigaremos mais adiante) que parece oferecer aos homens possibilidades de resistência aos vitupérios da fortuna. Assim, "o mesmo acontece com a fortuna, que demonstra a sua força onde não encontra uma virtù ordenada, pronta para resistir-lhe e voltar o seu ímpeto para onde sabe que não foram erguidos diques ou barreiras para contê-la". ${ }^{69}$

Este primeiro sentido apresentado por Maquiavel e apontado por ele como mais "geral" nos remete às possíveis modificações das circunstâncias que envolvem o corpo político e que, a priori, não dizem

66 MACHIAVELLI. Il Principe, XXV, p. 187: E questo voglio basti aver detto, quanto allo opporsi alla fortuna, in universali. Ma restringendomi piú a' particulari, dico come si vede oggi questo principe felicitare e domani ruinare, sanza avergli veduto mutare natura o qualità alcuna (...).

67 MACHIAVELLI. Il Principe, XXV, p. 187: E assimiglio quella a uno di questi fiumi rovinosi che, quando si adirano, allagano e'piani, rovinano li arbori e li edifizi, lievano da questa parte terreno, pongono da quella altra; ciascuno fugge loro dinanzi, ognuno cede all'impeto loro sanza potervi in alcuna parte ostare.

68 MACHIAVELLI. Il Principe, XXV, p. 187: E, benché sieno cosí fatti, non resta però che gli uomini, quando sono tempi queti, non vi potessino fare provedimento e con ripari e con argini: in modo che, crescendo poi, o eglino andrebbono per uno canale o l'impeto loro non sarebbe né sí dannoso né sí licenzioso.

69 MACHIAVELLI. Il Principe, XXV, p. 187: Similmente interviene della fortuna, la quale dimostra la sua potenza dove non è ordinata virtú a resisterle: e quivi volta e' sua impeti, dove la sa che non sono fatti gli argini né e' ripari a tenerla. 
respeito diretamente ao governante. No entanto, se não lhe dizem respeito a priori poderão recair sobre ele, pois ele terá que reagir aos efeitos da enchente e tentar evitar que os efeitos da fortuna no corpo político desencadeiem efeitos secundários sobre seu governo. Não se pode dizer também que os efeitos da fortuna, ao atuarem sobre um determinado ator político, não desencadearão efeitos secundários sobre o corpo político. Isto nos leva a crer que, apesar de haver uma separação clara entre o geral e o particular e de a fortuna os afetar de forma distinta, não é possível isolar estes âmbitos e pensá-los isentos de interferência mútua. Ao contrário, são complementares, e talvez a forma mais clara de perceber isto seja por meio das metáforas que os ilustram.

A segunda metáfora apresentada por Maquiavel diz respeito à fortuna em particular, ou seja, quando ela afeta diretamente os indivíduos. Nesta segunda metáfora, Maquiavel apresenta inicialmente alguns casos em que determinados homens perderam o poder por não se adequarem às variações dos tempos. Somente no final do capítulo ele nos oferece a metáfora:

afortuna é mulher e é necessário para dominá-la bater-lhe e contrariá-la. Vê-se que ela se deixa vencer mais pelos que agem assim do que pelos que agem friamente; e, como mulher, é sempre amiga dos mais jovens, porque são menos prudentes, mais ferozes e a dominam com maior audácia. $^{70}$

Talvez a constatação mais imediata que a passagem nos traz é que, ao pensar a fortuna ${ }^{71}$ sob "seus aspectos mais particulares", Maquiavel nos remete a uma força não mais inexorável e, portanto, passível de dominação. Esta metáfora pode ser vista como o ponto em que Maquiavel se distancia de fato da tradição humanista. Bignotto, a este respeito, nos diz que "embora implique um certo saber a virtù não é, como queria Petrarca, o resultado de uma boa preparação para a vida comum". ${ }^{72}$

70 MACHIAVELLI. Il Principe, XXV, p. 189: (...) perché la fortuna è donna ed è necessario, volendola tenere sotto, batterla e urtarla. $E$ si vede che la si lascia piú vincere da questi, che da quegli che freddamente procedono: e però sempre, come donna, è amica de' giovani, perché sono meno respettivi, piú feroci e con piú audacia la comandano.

71 Embora seja ao tratar dos homens em particular que Maquiavel nos apresente a fortuna como mulher, deixamos de lado a questão do gênero. Reconhecemos que a questão do gênero é interessante, especialmente quando nos deparamos com determinados títulos de capítulos, tal como "De como se arruína um Estado por causa de mulher" (MACHIAVELLI. Discorsi, III, p. 26), mas entendemos que tal questão não diz respeito ao nosso assunto, pelo menos não de forma direta e, por isso, a deixamos de lado aqui. No que diz respeito à questão do gênero e sua relação com a questão da fortuna, ver PITKIN. Fortune is a Woman: Gender \& Politics in the thoght of Niccolò Machiavelli.

72 BIGNOTTO. Maquiavel Republicano, p. 150. 
Além disso, devemos observar que, ao contrário do que nos indica a primeira metáfora, a segunda parece estar isenta das discussões cosmológicas que vimos anteriormente. Tal como afirma Parel, "a fortuna, considerada desta forma, não tem nenhuma conotação cósmica ou divina". ${ }^{73}$ Independentemente desta distinção, uma coincidência entre as metáforas e os sentidos da fortuna que nos são apresentados por meio delas nos indica a chave de compreensão do termo pelo menos no que diz respeito ao príncipe novo. Assim, se Maquiavel, ao apresentar a metáfora da enchente, sugere concluir restringindo-a à fortuna em geral, ao tratar da fortuna, no que ela diz respeito aos particulares, não chega a uma conclusão muito diferente. Em outras palavras, as duas metáforas nos conduzem a pensar que a força da fortuna pode ser pelo menos minimizada e que a autonomia humana diante das circunstâncias da vida seria efetiva, embora delimitada pela capacidade dos homens de resistir às modificações impostas pela fortuna. E, mesmo naquilo em que diz respeito ao modo como a fortuna, em geral, afeta o corpo político, atentar para a construção de diques de maneira a impedir que a fúria da fortuna produza tantos estragos depende do ator político e constitui tarefa deste tomado em sua particularidade.

O Príncipe, no entanto, não encerra a questão da fortuna. Já mencionamos aqui o pequeno texto de Maquiavel Di Fortuna, que trazia uma perspectiva mais sombria da liberdade de ação dos homens sujeitos aos vitupérios das rodas dos tempos. A análise do poema apresentada por Aranovich é categórica quanto ao seu tom determinista.

A conclusão a que Maquiavel chega, ao final do poema, é de que a Fortuna não proporciona a felicidade e de que é muito grande a dificuldade para completar o ciclo: à elevação segue-se a ruína e desta não se volta a encontrar elevação, mas sim a morte, que seria o destino dos que foram aprisionados pela Fortuna. ${ }^{74}$

O poema, de fato, nos remete à forma como os antigos a percebiam a fortuna. Ela era uma deusa boa, e os infortúnios resultavam em grande medida de sua ausência. Em outras palavras, tal como a deusa romana, a fortuna pode configurar-se como aquela que favorece os que estão perto dela. Sua ausência, neste sentido, propiciaria os infortúnios. Certamente o poema faz uma alusão à deusa romana da fortuna, porém, a mudança sutil do singular para o plural parece não ter sido feita de maneira fortuita. Bignotto, a este respeito, afirma que "a escolha da imagem das várias rodas não foi feita sem segundas intenções. Na tradição ocidental, o fato

73 PAREL. The Machiavelin Cosmos, p. 66.

74 ARANOVICH, P. F. Di Fortuna e a Fortuna em Maquiavel. "Cadernos de Filosofia Política", p. 228. 
de apresentar a fortuna como o mestre de uma roda serviu sempre para mostrar a inexorabilidade de suas decisões". ${ }^{75}$ Assim, ao multiplicar a figura da roda, Maquiavel parece ter lançado as primeiras premissas para começar a se apartar deste fatalismo tradicionalmente associado à ideia de fortuna. Premissas estas que parecem ter se tornado fecundas n'O Príncipe e, tal como veremos, também nos Discorsi, que nos falta ainda contemplar.

Nestes últimos, Maquiavel recupera a questão da fortuna de forma peculiar. Ele inicia o primeiro capítulo do segundo livro dos Discorsi discordando de Plutarco e Tito Lívio naquilo que diz respeito à grandeza de Roma ter sido fruto da fortuna. Este posicionamento assumido pelo autor parece se tornar mais definitivo ao longo da obra e termina por distanciá-lo, tal como veremos mais adiante, das definições clássicas assumidas pelos humanistas. Precisamos, neste ponto, atentar para o fato de que a relação que Maquiavel assume frente à tradição é, tal como vimos ao tratar da percepção do cosmos em seu tempo, repleta de nuances e, por vezes, demanda certa atenção. Tal como afirma Marie Gaille-Nikodimov a este respeito,

o fato de já ter a noção de fortuna uma longa existência até Maquiavel retomá-la não tira a importância do uso que ele faz dela e da difusão que ela ganha a partir de sua obra. Nela a fortuna aparece sobretudo como uma noção polissêmica. Suas múltiplas caracterizações nunca são unificadas e, deste modo, a ideia de fortuna permanece sempre misteriosa: ela não pode ser verdadeiramente conhecida e dominada, nem na prática e nem na teoria. ${ }^{76}$

Esta dificuldade parece emergir à medida que avançamos a leitura das páginas do autor. Uma passagem dos Discorsi, do capítulo intitulado "A fortuna torna cego o ânimo dos homens, quando não quer que eles se oponham a seus desígnios" parece exemplificá-la:

e a fortuna, quando quer realizar seus feitos, escolhe um homem que tenha tanto espírito e tanta virtù que perceba as ocasiões que ela lhe oferece. Assim também, quando quer provocar grandes ruínas, incumbe homens que as facilitem. E se houver alguém que possa obstar-lhe, ela o mata ou o priva de todas as faculdades de realizar algum bem. ${ }^{77}$

75 BIGNOTTO. Maquiavel Republicano, p. 146.

${ }^{76}$ GAILLE-NIKODIMOV. Machiavel, penseur de l'action politique, in: GAILLE-NIKODIMOV et MÉNISSIER, Lectures de Maachiavel, p. 264.

77 MACHIAVELLI. Discorsi, II, 29, p. 406: Fa bene la fortuna questo, che la elegge uno uomo, quando la voglia condurre cose grandi, che sia di tanto spirito e di tanta virtú che ei conosca quelle occasioni che la gli porge. Cosí medesimamente, quando la voglia condurre grandi rovine ella vi prepone uomini che aiutino quella rovina. $E$ se alcuno fusse che vi potesse ostare, o la lo ammazza o la lo priva di tutte le facultà da potere operare alcuno bene. 
Muitas questões podem ser pensadas a partir dessa passagem. $\mathrm{O}$ que nos salta aos olhos é a retomada do fatalismo da fortuna sobre os homens. Ilustra, mediante os efeitos do que ela é capaz, a força da fortuna em fúria por ter sido contrariada. Além dele, nos conduz a refletir sobre os desígnios da fortuna que nem sempre tendem a se efetivar nocivos aos homens. Em um primeiro momento, o autor sugere que ela pode favorecêlos. Porém, favorecê-los enquanto suas ações contribuem aos seus desígnios. Permanecemos em um cenário dominado pela inexorabilidade da fortuna. Por fim, nos faz pensar - e aqui talvez tenhamos alguma possibilidade de compreender melhor as anteriores - na relação que fortuna estabelece com a virtù.

Acreditamos que o fatalismo desta passagem não implica uma retomada da concepção tradicional e tais dificuldades demandam passos cautelosos. Percorrendo as páginas dos Discorsi, encontramos trechos mais elucidativos. No terceiro livro, tal qual havia feito n'O Príncipe, o autor retoma o tema da necessidade de se adaptarem as ações dos atores políticos às variações dos tempos. O nono capítulo, "De como é preciso variar com os tempos quem quiser sempre ter boa fortuna", parece retomar o mesmo tom que marcara as páginas d'O Príncipe. Nele Maquiavel afirma que

já considerei várias vezes que a razão da má e da boa fortuna dos homens vem do ajuste de seu modo de proceder com os tempos: porque se percebe que alguns homens, em suas ações, procedem com ímpeto, e outros com circunspeção e cautela. E como, nestes dois modos, são ultrapassados os limites convenientes, por não se observar a verdadeira via, em ambos se erra. Mas erra menos e tem a fortuna próspera quem, como já disse, ajusta seu modo aos tempos e sempre procede conforme o força a natureza. ${ }^{78}$

Vimos uma passagem semelhante n'O Príncipe, mais especificamente na ocasião em que Maquiavel metaforicamente tomava a fortuna por mulher. A conclusão aqui não parece ser diferente da de lá: sugere aos homens a possibilidade de se sobreporem de alguma forma à força da fortuna. Isto seria possível em grande medida pela adequação de suas ações, assim como pela audácia da tentativa de sobrepujar aquilo que se considerava ter força inexorável. Já sabemos das dificuldades de se

78 MACHIAVELLI. Discorsi, III, 9, p. 448: Io ho considerato piú volte come la cagione della trista e della buona fortuna degli uomini è riscontrare il modo del procedere suo con i tempi: perché e'si vede che gli uomini nelle opere loro procedono, alcuni con impeto, alcuni con rispetto e con cauzione. E perché nell'uno e nell'altro di questi modi si passano e'termini convenienti, non si potendo osservare la vera via, nell'uno e nell'altro si erra. 
efetivar esta adequação, assim como da tendência dos homens em repetir suas ações. Porém, tal como afirma Bignotto,

para pensarmos a ação política é preciso não creditar à fortuna mais do que ela pode efetivamente fazer. Se reconhecemos que a ação humana é criadora de nossas realidades, é preciso seguir até o fim dessa determinação e chegar à conclusão de que todo problema reside na virtù, e não na fortuna, que aparece no curso de nossos atos apenas como uma força de oposição, como um obstáculo a ser transposto. ${ }^{79}$

A fortuna pode favorecer ou prejudicar corpo políticos ou indivíduos. Não é ela, no entanto, que necessariamente determina a conclusão do desenrolar da história. Este papel pode ser incorporado pela virtù que se lhe impõe. Esta perspectiva parece constituir a conclusão a que Maquiavel nos conduz tanto n'O Príncipe quanto nos Discorsi. E, se no primeiro acreditávamos que o autor considerava como ponto de partida a inexorabilidade da fortuna no intuito de dialogar ou mesmo seduzir seus interlocutores, no segundo acreditamos que a fortuna pode ser pensada como inexorável não por ser efetivamente fatal, mas por ser sua inexorabilidade inversamente proporcional à virtù dos homens. Assim, se a virtù ${ }^{80}$ é a chave que nos falta para a compreensão da questão da fortuna ${ }^{81}$.

Enquanto a maioria de seus contemporâneos considerava que o homem não tem absolutamente nenhuma chance de se sobrepor à fortuna, Maquiavel rompe com esta perspectiva determinista e insiste em propor meios em que se proteger da fortuna configura-se viável. Assim, metade cabe à fortuna e, nesta metade, não nos cabe interferência. É a "roda dos tempos", implacável, tal como a "força das águas durante uma grande enchente". ${ }^{82}$ Sobre essa parte conselhos não seriam cabíveis. No entanto, se os homens assumem a responsabilidade sobre quase metade

79 BIGNOTTO. Maquiavel Republicano, p. 147.

80 Não trataremos as especificidades do termo virtù neste trabalho. Para uma boa compreensão do termo Cf. PRICE, R. "The Sensesofvirtù in Machiavelli". European Studies Review, 3, p. 315-345.

81 Cristian Ion nos ajuda a compreender a importância desta relação ao apontar a forma mais comum a que nos referimos à virtù, opondo-a, por sua vez, às especificidades que ela ganha quando contraposta à fortuna. De acordo com ela, "quando dizemos virtude, é frequentemente num sentido geral, tomando-a de modo genérico para tudo que revela a capacidade humana de realizar um objetivo, de modificar os eventos, de resistir à desconstrução". (ION. Conquérir, Fonder, se mantenir. In: GAILLE-NIKODIMOV; MÉNISSIER.Lectures de Machiavel, p. 119). Por outro lado, quando relacionada à fortuna, ela parece assumir certa especificidade. Seguindo a argumentação de Ion, "a virtude maquiaveliana no seu senso forte, ligada à perspicácia na decisão da ação, se revela através do seu reencontro com a fortuna e a capacidade de saber a ocasião". (ION, Conquérir, Fonder, se mantenir. In: GAILLE-NIKODIMOV; MÉNISSIER. Lectures de Machiavel, p. 119.)

82 Ver MACHIAVELLI. Il Principe, XXV. 
das coisas que lhes dizem respeito, há ainda muito a ser controlado. Podemos pensar, neste sentido, que Maquiavel percebe, e alerta seus leitores, que há duas opções. A primeira seria deixar de lado essa questão, uma vez que a roda dos tempos é, por definição, desgovernada e implacável. Assim, nenhum esforço sobre o "controle do incontrolável" traria êxito e, tomando como parâmetro esta primeira opção, não haveria o que fazer a não ser se entregar de bom grado à fúria do "destino". Já a segunda opção seria tentar atrair os favores da fortuna, fazer com que a deusa não resista a determinados caprichos. Nesse sentido, atrair os privilégios que poderiam ser recebidos da fortuna acabaria por exigir um modo de proceder. Por isso, esse tema é de grande importância para Maquiavel, atrair a bondade da deusa exige um determinado modo segundo o qual se deve proceder, ou seja, pode-se então tecer conselhos a um governante que tenha pretensões em relação aos bens dos quais dispõe a fortuna. Se, no que diz respeito à primeira, não se pode fazer nada, no caso da segunda, ao contrário, há muito que se pensar. Tal como afirmam D'Istria e Relang, "a vida de um homem, assim como de um Estado, é esta necessidade ingrata e sem cessar urgente que consiste, estando ela mesma no tempo, em afrontar as circunstâncias que os tempos nos depositam nos braços". ${ }^{83}$ Afrontar as circunstâncias pode ser pensado também como agir de acordo com elas, superá-las. Muitas passagens do texto de Maquiavel chamam nossa atenção para a necessidade de se adequar às circunstâncias. No Livro III dos Discorsi, por exemplo, Maquiavel faz a seguinte afirmação: "já considerei várias vezes que a razão da má e boa fortuna dos homens vem do ajuste do seu modo de proceder com os tempos. (...) Erra menos e tem a fortuna próspera quem, como já disse, ajusta seu modo aos tempos (...)". ${ }^{84}$ Agir de acordo com o seu tempo, ou ainda, agir de acordo com as circunstâncias de seu tempo seria a expressão máxima da virtù e, no entanto, é também o que se deve fazer para tentar atrair os gracejos da fortuna. Parece que agora Maquiavel torna mais clara essa relação entre virtù e fortuna ${ }^{85}$.

No entanto, de acordo com o autor, naquilo que diz respeito àqueles que detêm o poder, há vários modos de agir capazes de conduzir o governante aos seus objetivos. Modos às vezes contrários podem atingir o mesmo resultado, bastando para isso que estejam de acordo com os

83 D'ISTRIA; RELANG. L'art Politique chez Machiavel, p. 143.

84 MACHIAVELLI. Discorsi, III, 9, p. 448: Io ho considerato piú volte come la cagione della trista e della buona fortuna degli uomini è riscontrare il modo del procedere suo con i tempi (...). Ma quello viene ad errare meno ed avere la fortuna prospera che riscontra, come ho detto, con il suo modo il tempo (...).

85 Trata-se de um par conceitual que se tornou clássico ao longo do legado maquiaveliano. Restringiremo-nos apenas em apontá-lo. 
tempos. Mas dois governantes podem agir da mesma maneira e um deles fracassar enquanto o outro conquista seu objetivo. Para Maquiavel, a explicação é simples: um agiu de acordo com as variações dos tempos, enquanto o outro não soube lhes dar a atenção devida. Tal fato, para o pensador de Florença, "não acontece por outra razão senão pela natureza dos tempos, com a qual se conformam ou não aos procedimentos deles". ${ }^{86}$ $\mathrm{Na}$ sequência do texto, o autor afirma que

dois agindo diferentemente alcançam o mesmo efeito, e dois agindo igualmente, um vai direto ao fim e o outro não. Disso dependem também as diferenças da prosperidade, pois se um se conduz com cautela e paciência e os tempos e as coisas lhe são favoráveis, o seu governo prospera e disso lhe advém felicidade. Mas se os tempos e as coisas mudam, ele se arruína, porque não alterou o modo de proceder. (...) Se mudasse de natureza, conforme o tempo e as coisas, não mudaria de fortuna. ${ }^{87}$

Os Discorsi guardam passagens tão esclarecedoras quanto as d'O Príncipe. Neles Maquiavel conclui que justamente "por isso a fortuna dos homens varia: ela altera os tempos, mas nem todos modificam sua conduta". ${ }^{88} \mathrm{E}$, poderíamos dizer que "mudar", "modificar um determinado modo de agir", é de grande dificuldade. Não se pode, no entanto, atribuir a fortuna uma força maior do que ela tem. E, se de fato esta força descomunal lhe é atribuída, deve-se à dificuldade humana de "mudar". Mas esta é uma dificuldade humana e não propriamente uma das características da força da fortuna.

Precisamos admitir que, apesar da força da fortuna e de sua capacidade de alterar as circunstâncias, é dos homens ou dos Estados a responsabilidade de obtenção do êxito ou de sucumbirem diante das variações dos tempos. Tal como procuramos mostrar aqui esta não é conclusão definitiva em seu tempo. A fortuna era tomada como a

86 MACHIAVELLI. Il Principe, XXV, p. 188: (...) il che non nasce da altro, se non da la qualità de' tempi che se conformano, o no, col procedere loro.

87 MACHIAVELLI. Il Principe, XXV, p. 188: (...) che dua, diversamente operando, sortiscono el medesimo effetto, e dua equalmente operando, l'uno si conduce al suo fine e l'altro no. Da questo ancora depende la variazione del bene; perché se uno, che si governa con rispetti e pazienza, e' tempi e le cose girando in modo che il governo suo sia buono, e' viene felicitando, ma se e' tempi e le cose si mutano, rovina, perché e' non muta modo di procedere. (...) se si mutassi natura con e' tempi e con le cose, non si muterebbe fortuna.

88 MACHIAVELLI. Discorsi, III, 9, p. 450: (...) donde ne nasce che in uno uomo la fortuna varia, perché ella varia i tempi ed elli non varia i modi. 
grande responsável pelo êxito ou fracasso. Maquiavel parece inverter essa lógica conferindo à ideia de virtù a capacidade de 'atrair a fortuna e de dominá-la'. Tendo em vista melhor compreender os liames desta inversão, assim como a continuidade e descontinuidade do pensamento de Maquiavel com seu tempo, procuramos apresentar, por meio dos trabalhos de alguns autores que desenvolveram estudos em torno desta questão, interpretações que se tornaram clássicas ao longo da história. Partimos assim do trabalho de autores que se detiveram sobre o termo e seus usos, especialmente os trabalhos que se detiveram no período que antecede a obra de Maquiavel. Nesta primeira parte nosso objetivo era apenas reconstruir as hipóteses interpretativas do termo em questão, mostrando os aspectos convergentes com a tradição e também aqueles que a transgrediram. As especificidades e as "novidades" da fortuna, tal como apresentada por Maquiavel, foram assim apresentadas por oposição à tradição. Por isso nos detivemos longamente nas análises de historiadores e comentadores da obra de Maquiavel que procuraram analisar o contexto de sua obra. É exatamente esta relação que Maquiavel estabelece com a tradição que possibilita mostrar que quanto mais se pensava a força da fortuna como inexorável, menor era o papel e a responsabilidade do homem, assim como do próprio governante, sobre as ações humanas no terreno da política.

Procuramos analisar os dois sentidos centrais que o termo fortuna assume na obra de Maquiavel, ambos apresentados por metáforas, a saber, a metáfora do rio e a da mulher. Neste ponto foi possível observar que certa tensão que parece acompanhar os comentários tecidos a partir das metáforas apresentadas por Maquiavel. A fortuna seria em Maquiavel uma força tão inexorável quando era para os autores clássicos que o antecedem? A roda da fortuna, também para Maquiavel, gira de modo a produzir inconstâncias sem possibilidade de superação? Não nos alinhamos a esta hipótese interpretativa. Para tentar esclarecê-la recuperamos textos que nos ajudaram a compreender melhor o contexto em que Maquiavel escrevera sobre a questão da fortuna. E, a partir desta melhor compreensão deste momento em que havia certa tensão no uso deste termo, as afirmações de Maquiavel, que procuramos analisar mais tardiamente, puderam ser tomadas de modo mais definitivo e é justamente esta a pretensão deste trabalho, romper com a perspectiva de que a fortuna se configura como uma força absolutamente inexorável.

O terreno da política é, sem dúvida, o da contingência. Portanto, não se pode prever o futuro, não se pode ignorar as reviravoltas que a fortuna é capaz de introduzir a qualquer momento. Mas é possível ao ator político se impor aos seus reveses pela ação de virtù. Tanto a metáfora do rio quanto a da mulher, ambas analisadas na segunda parte deste trabalho, 
nos conduziram a esta conclusão. Nestas metáforas é possível perceber o esforço de Maquiavel para mostrar a possibilidade da ação humana como efetivamente autônoma. A ação do homem é capaz de imprimir sua marca no terreno na contingência. Deste modo, o ator político não precisa ser uma vítima da contingência, mas um ator autônomo: que edifica diques e barragens para impedir que a força das contingências próprias da vida pública o destrua, e destrua a organização política na qual ele se insere. Além disso, para Maquiavel, agir de acordo com as circunstâncias é o agir caracterizado pela virtù e, esse agir, independentemente de que direção segue, tem uma chance maior de ser acompanhado, ou mesmo amparado pela fortuna.

\section{Referências}

ARANOVICH, P. F. "Di fortuna e a fortuna em Maquiavel". Cadernos de Filosofia Política, v. 18, n. 1, 2011, p. 221-230.

BARTHES, R. A aventura semiótica. Tradução de Mario Laranjeira. São Paulo: Martins Fontes, 2001.

BIGNOTTO, N. Maquiavel. Rio de Janeiro: Jorge Zahar, 2003.

BIGNOTTO, N. Maquiavel Republicano. São Paulo: Loyola, 1991.

CARDOSO, S. "Que República? Notas sobre a tradição do governo 'misto'”. In: BIGNOTTO, Newton (Org.). Pensar a República. Belo Horizonte: Ed. UFMG, 2000.

CASSIRER, E. Individu et cosmos dans la philosophie de la Renaissance. Tradução. de P. Quillet. Paris: Éditions de Minuit, 1983.

COLONNA D'ISTRIA, G.; FRAPET, R. L' art politique chez Machiavel. Paris: J. Vrin, 1980.

DEANE, H. The political and social ideas of St. Augustine. New York: Columbia Univresity, 1963.

FARAKLAS, G. Machiavel: le pouvoir du Prince. Paris: Presses Universitaires de France, 1997.

GAILLE-NIKODIMOV, M. Machiavel, penseur de l'action politique. In: GAILLENIKODIMOV, M.; MÉNISSIER, T. Lectures de Machiavel. Paris: Ellipses, 2006.

GARIN, E. Le zodiaque de la vie: polemiques antiastrologiques a la Renaissance. Traduit de l'italien par Jeannie Carlier. Paris: Les Belles Lettres, 1991.

ION, C. "Conquérir, Fonder, se mantenir". In: GAILLE-NIKODIMOV, Marie; MÉNISSIER, Thierry. Lectures de Machiavel. Paris: Ellipses, 2006.

LEFORT, C. Le travail de l'oeuvre: Machiavel. Paris: Gallimard, 1972.

MANENT, P. Naissances de la politique moderne: Machiavel, Hobbes, Rousseau. Paris: Gallimard, 2007.

MANSFIELD, H. C. Machiavelli's virtue. Chicago; London: The University of Chicago Press, 1996.

MARKUS, R. A. Saeculum: history and society in theology of St. Augustine. Cambridge: Cambridge University Press, 1970. 
F. R. B. de Souza - Maquiavel: do cosmos medieval ao renascentista...

MÉNISSIER, T. Le Vocabulaire de Machiavel. Paris: Ellipses, 2002.

MACHIAVELLI. Opere. A cura di Conrado Vivanti.Torino: Einaudi-Gallimard, 1997. 3v. MAQUIAVEL. O Príncipe. São Paulo: Martins Fontes, 2004.

MAQUIAVEL. Discursos a primeira década de Tito Lívio. São Paulo: Martins Fontes, 2007.

MAQUIAVEL. História de Florença. São Paulo: Martins Fontes, 2007.

PANCERA, C. G. K. Maquiavel entre Repúblicas. Belo Horizonte: Ed. UFMG, 2010.

PAREL, A. J. The Machiavellian cosmos. New Haven; London: Yale University Press, 1992.

PITKIN, H. F. Fortune is a woman: Gender \& politics in the thought of Niccolò Machiavelli. Chicago; London: The University of Chicago Press, 1999.

POCOCK, J.G. A. The Machiavellian moment. Princeton: Princeton University Press, 1975.

POLYBE. Histoires, Livre VI. Paris: Les Belles Lettres, 2003.

PRICE, R. "The senses of virtù in Machiavelli". European Studies Review, v. 3, 1973, p. 315-345.

RÉLANG, A. "La dialectique de La fortuna et de La virtù chez Machiavel". Archives de Philosophie, v. 66, n. 3, 2003, p. 649-662.

SFEZ, G. Machiavel, la politique du moindre mal. Paris: Presses Universitaires de France, 1999.

SKINNER, Q. Visions of politics. Renaissance virtues. Cambridge: Cambridge University Press, 2002. v. 2.

STRAUSS, L. Thoughts on Machiavelli. Chicago; London: University of Chicago Press, 1958.

TARANTO, D. Le virtù della politica: civismo tra Machiavelli e gli Antichi. Napoli: Bibliopolis, 2003.

VAROTTI, C. "Une écriture fondée sur l'experience". Tradução do italiano por Marie Gaille-Nikodimov. In: GAILLE-NIKODIMOV, M.; MÉNISSIER, T. Lectures de Machiavel. Paris: Ellipses, 2006.

ZARKA, Y. C. Figures du pouvoir. Études de philosophie politique de Machiavel à Foucault. Paris: Presses Universitaires de France, 2001a.

ZARKA, Yves Charles; MÉNISSIER, Thierry. Machiavel, le Prince ou le nouvel art politique. Paris: PUF, 2001.

\section{Endereço postal:}

Coordenação do Curso de Filosofia da UFAL

ICHCA (Insituto de Ciências Humanas, Comunicação e Artes)

UFAL - Universidade Federal de Alagoas - Campus A. C. Simões

Av. Lourival Melo Mota, s/n, - Cidade Universitária

57072-900 Maceió, AL, Brasil

Data de recebimento: 29/01/2013

Data de aceite: 28/09/2013 